\title{
Retraction: Diagnostic value of erythrocyte sedimentation rate levels as a predictor of staple- line leakage in bariatric surgery
}

\author{
Milad Kheirvari', Isa Akbarzadeh², Sahar Eshghjoo³, Mohammadreza Yazdannasab', Robert C. Alaniz ${ }^{3}$, \\ Sara Hosseini ${ }^{4}$, Taha Anbara ${ }^{4}$
}

American University of Beirut Medical Center, Beirut 1107-2020, Lebanon.

Correspondence to: Dr. Taha Anbara, Department of Surgery, Erfan Niayesh Hospital, Tehran 1476913814, Iran.

E-mail:drtahaanbara@yahoo.com

Received: 4 Feb 2020 Accepted: 4 Feb 2020 Published: 12 Feb 2020

The original article was published on 16 Jan 2020.

This article ${ }^{[1]}$ has been retracted by authors because there are unresolved issues relating to authorship and contents. All the authors confirmed this retraction.

\section{REFERENCE}

1. Kheirvari M, Akbarzadeh I, Eshghjoo S, Yazdannasab M, Alaniz RC, Hosseini S, Anbara T. Diagnostic value of erythrocyte sedimentation rate levels as a predictor of staple-line leakage in bariatric surgery. Mini-invasive Surg 2020;4:3.

(c) (i) The Author(s) 2020. Open Access This article is licensed under a Creative Commons Attribution 4.0 International License (https://creativecommons.org/licenses/by/4.0/), which permits unrestricted use, sharing, adaptation, distribution and reproduction in any medium or format, for any purpose, even commercially, as long as you give appropriate credit to the original author(s) and the source, provide a link to the Creative Commons license, and indicate if changes were made.

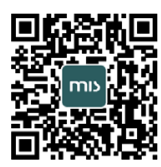

